\title{
Difference in Kind: \\ Observations on the Distinction of the Megista Gene
}

\author{
David Ambuel \\ University of Mary Washington
}

In the Theaetetus, Socrates observes how the discussion has led its participants bit by bit to fall "unexpectedly into the middle," pulled between Eleatic and Heraclitean doctrine (kata smikron gar proiontes lelēthamen eis to meson peptōkotes) (180e), adding the ironic hope that examination of one side will prove persuasive and rescue them from the other, since, should it turn out that neither doctrine is worthy (metrion) (181b), Socrates and Theaetetus surely cannot presume to best them. ${ }^{459}$ Theodorus, in response, finds it imperative to carefully examine (diaskepsasthai) both opposing forces, and they agree to examine each in turn. Yet the Theaetetus, occupied extensively with Heraclitean metaphysics, defers consideration of Parmenides. (183e) Eleaticism is the issue in the Sophist, and in this way the two dialogues are complementary, the Theaetetus dialectically addressing Heraclitus and the Sophist Parmenides. ${ }^{460}$ Also at issue in each dialogue is a distinction, perhaps also complementary: in the Theaetetus, the distinction between knowledge and opinion, in the Sophist, that between being and not-being.

Heraclitus asserts a universal flux - the only reality is change; therefore, "things" are ever different and no sameness is to be identified anywhere. Parmenides denies any change in any respect: the uncaused eternal sameness of being entails the impossibility of difference in any sense. Ironically, this tugging in opposite directions is also a push in one direction. Either, in Plato's analysis, leads to the impossibility of discourse, thought, or meaning. Following the Theaetetus' argument the absence of any constancy or sameness makes the employment of any word-including the simple "this", or even "thus"--an absurdity (Theaetetus, 183b). A parallel consequence follows from the Eleatic denial of any difference: the absolute unity of being itself renders it impossible even for the word "being" to be. (244d)

The Eleatic-Heraclitean impasse remarked upon in the Theaetetus reappears in the Sophist with the formulation of a response to the challenge of Eleaticism. That response is introduced by a discussion of "combinations" that will both introduce and be illustrated by some of the megista gene, the "greatest kinds," which, by the conclusion of the analysis, will number five: "rest," "motion," "being," "sameness," and "other."

\footnotetext{
459 They agree to examine each in turn. Insofar as the discussion of Parmenides is curtailed in the Theaetetus, and prominent in the Sophist, the latter dialogue could be taken as the continuation of this task, in which case, in light of the perplexities, it must be said the desired extrication has failed. The Theaetetus remark is further ironic in that, as interpreted for Plato's purposes, Heraclitus and Parmenides appear diametrically opposed, pulling them in opposite directions, whereas they are in fact pulling in the same direction insofar as both doctrines imply the same metaphysical inadequacy: a kind of nominalism that renders the distinction impossible.

$460 \quad$ I am setting aside here any questions as to whether or not Plato has accurately represented the argument of the historical Parmenides or of the historical Heraclitus. Along with this, also set aside is the question whether, if there is a misrepresentation, it is unwitting or intended. Instead, for present purposes, Eleatic metaphysics or Heraclitean metaphysics should be taken to mean the metaphysics as Plato (re)conceives them for purposes at hand in the present dialogue.
} 
The philosopher, the reader is told, must neither accept the account by which being is entirely at rest and always the same (regardless whether such an account posits a plurality of unchanging forms or a monism), nor the account that asserts all being is ever in motion. (249c-d) Either account would render all accounts unintelligible, by stripping mind from reality (noun mèdeni peri médenos einai médamou). (249b) The advocates of absolute rest and the advocates of absolute motion represent respectively a metaphysics resting on Eleatic inspiration and Heraclitean inspiration. ${ }^{461}$ And so "being" is neither "rest" nor "motion", but both together.

The concept "combination" that is employed to define the greatest kinds is introduced subsequent to this conclusion that "being" cannot be identical to "rest," nor identical to "motion," and therefore must be something distinct. That is, it must be possible to intelligibly think and state that "motion is" (or "moving things exist," or "this particular moving thing exists") where the attribute "being" has some relation to but is not identical to the subject. This leads the Visitor to his exhortation at 251a that might initially strike the reader as an unanticipated transition: the exhortation to examine how we call the same thing by many names (legōmen de kath' hontina pote tropon pollois onomasi tauton touto hekastote prosagoreuomen).

But that question is the question about the very possibility of thought and discourse, threatened by the two metaphysical extremes, and here, again, the examination of "combination" begins by rejecting two extremes: it would be equally untenable to assert either that everything combines or to assert that nothing combines.

The thought that nothing combines might be cast as a notion of Eleatic inspiration: entity simply is what it is; combination with anything would entail that something simultaneously is and is not something else. An utter absence of combination issues from a metaphysics of Parmenides, or from a sophistry of the "latelearners", such as an Antisthenes, who denies the possibility of attributing any name to a subject other than its own.

The thought that everything combines, on the other hand, issues from a metaphysics of Heraclitus: by the assertion of universal flux, a radicalization of pluralism, every so-called "individual" is changed at every instant and so is called with equal justification by one property or its opposite. The analogous doctrine in sophistry is the relativism of Protagoras as interpreted in the Theaetetus.

This is important for consideration of the distinction between being form and having form. If, with Parmenides, there is only the most barren oneness and selfsameness, with no pluralities in which unities are to be discerned, or, with Heracleitus, there is only sheer difference, and no unity that extends through it, then there can be no coherent conception of entity that is both something in itself and can be characterized in various respects. (That is the case regardless whether "entity" is understood here on the model of Platonic form, or Aristotelian substance, or something else.) The totality of combination or the nullity of combination both amount to a denial of all relation, which includes relation between one and many, between form and particular, between subject and predicate, or also the ontologically disparate relation between original and dependent image.

This sharpens the Sophist's earlier challenge to the possibility of false statements: to say what is false is to say what is not and therefore requires a conception

\footnotetext{
461 Broadly conceived, broad enough to include derivative arguments that seem little more than a poor parody of the Parmenidean model, to wit, the "late learners" mentioned at 251b-c. The Visitor explicitly frames the discussion so broad and unspecific that it will address "all who have ever stated anything whatsoever about being" (hina toinun pros hapantas hēmin ho logos hèi tous pōpote peri ousias kai hotioun dialexthentas). (251c)
} 
of "not-being," which, however, can neither be thought nor said intelligibly. If no statement can be false, then no statement can be intelligible. The examination of combinations will provide, after a fashion, a response to the dilemma: false statements state not things that are not, but rather things that are, but are other, that is, state only what is, thought it is different from what is stated.

The combinations of kinds have remained an enduring puzzle. Nevertheless, without straying into the finer points that separate interpretations, but instead speaking in broad generality, it may be observed that a common focus of attention is the establishing of a distinction. For the present purposes, let this distinction be painted in the broadest strokes as that between what it means to be a form (character, property, kind) and what it means to have a form (character, property, kind). The distinction that is here sketched in greatest generality encompasses within it multiple possibilities for narrower and more determinate variations.

The distinction might be determined as one emphasizing its ontological aspect. It might, for example, be specified as the differentiation of that which is absolute and that which is relative. Or, alternatively, it could be seen as an indication of distinguishable senses of "not-being," namely as a definite "entity" that is the opposite of "being" (and therefore incoherent and unthinkable) or as alterity, which always indicates some relation, some difference from. ${ }^{462}$ Frequently, on the other hand, the distinction is fixed not as an ontological one, but rather as a purely grammatical and logical one. Such an interpretation sees in the Theaetetus and the Sophist an emerging maturity in logic: the lack followed by a discovery of a way to distinguish identity from predication, two distinct senses of the verb "to be," revealed in the concluding identification of not-being with difference, which marks the way to the final definition of the sophist. ${ }^{463}$

The following remarks will examine this distinction, not in one of its determinate variants, but in the general form. It will be seen that the distinction in the Sophist is not discovered or newly devised, but rather the object of a studied ambiguity that is a pointed, if indirect, critical encounter with the type of metaphysical assumptions that exclude it. Against this, one might take pause due to the appearance that the distinction in one form or another answers the Sophist's conundrum about false statements. But any interpretation that takes the dialogue's resolution as an authentic solution is confronted by insurmountable difficulties to be found in the structure of the dialogue's analysis of the combination of kinds. ${ }^{464}$

\footnotetext{
$462 \quad$ Cf. O'Brien (1995).

463 For this style of interpretation, see, for example, Hamlyn (1955), for whom communion of kinds is an awkward and imperfect advance in logic; Ackrill (1955), for whom it is an attempt to explain the conditions for the meaning of words; prominent also in the same interpretive tradition the would read the Sophist as a study in the grammar of the verb "to be" are Frede (1967), and Owen (1971). The notion that the source of the puzzles can be found in a confusion about propositions dates from much earlier: see Campbell (1883), Appendix E.

464 An interpretation that perceives a genuine solution rather than an aporetic conclusion to the dialogue, apart from the dialectical structure of the combinations of kinds, which is the topic of this paper, is unsatisfactory in two ways, merely noted here, and not pursued in greater detail. First, as a "solution" the resolution offered to the problem of false statements, if it answers any problem, answers a problem other than the one stated. The issue was to find a satisfactory account of the image as something that is real in some sense, but less real than the kind of reality that is real in itself and not a dependent and derivative image. The resolution makes no attempt to account for degrees of reality, but instead explicitly drops any attempt to confront the concept of "not-being" as the opposite of "being." The final account, consequently, shows a way to call "Theaetetus sits" true and "Theaetetus flies" false, but not a way to explain how "Leprechauns are not" is true or "Theaetetus is not" is false. Secondly, there is nothing new, either emerging or revolutionary, about the distinction. As in the Republic passages cited above, Plato
} 
This marks the concentration of the following observations, which are intended to offer an analysis of the "communion of kinds," with attention directed to the manner in which the five megista gene are distinguished from each other. Here, too, the focus will be on the distinction that the passage signals. However, when one looks to the way in which the kinds are sorted out one from the other, it will become evident that the passage does not introduce a distinction, much less a new one, but rather is a carefully structured exercise in studied ambiguity: departing from the initial opposition of rest to motion, each step in the argument distinguishing the kinds simultaneously assumes and denies the distinction between being a character and having a character.

\section{Method of distinction}

The greatest kinds are distinguished principally on the basis of possibilities of combination: if kind $\mathrm{A}$ and kind $\mathrm{B}$ do not match completely in their respective mixing relations, then they must be different kinds. The exception to the pattern is the starting point: "rest" and "motion" are distinguished on the grounds that they are completely opposed one to the other (enantiōtata, 250a).

Four points should be noted about "rest" and "motion," which are distinguished before they are called "kinds" or "just." 1) The opposition of rest to motion suggests a spatial metaphor, and is at points employed in a manner that underscores the metaphor, e.g., the assertion that it would be an absurd consequence to conclude that "rest moves" or "motion rests"; nevertheless, throughout the passage as a whole, the terms evince a conscious vagueness both in terms of reference - does "rest" designate a "kind" as one entity in itself, or something that is physically at rest, or a collection of things at rest? ${ }^{465}$ —as well as in terms of connotation-"motion" could conceivably designate "change" not only spatial, but qualitative or other change, insofar as it is initially introduced as a mark of dynamis, of power, and is associated with "life," "mind," and "soul.",466 2) "Rest" and "motion" are excluded from each other as opposites, and so, by implication, in virtue of their opposed natures. Later all distinctions of kind from kind will be attributed to participation in the kind "difference" and explicitly not in virtue of a kind's own nature. 3) The opposition of "rest" to "motion" grounds the absolute impossibility of their combination. This assumption, namely that "rest" and "motion" as opposites do not combine, will be a necessary assumption for establishing each of the three remaining gene as distinct kinds. And the assumption will, at the conclusion, be retracted. That the assumption grounding the distinction of kinds is, in the end, rejected as ill-founded is the first signal that the communion of kinds is a dialectical tool, not the establishment of new doctrine. 4) The distinction of kinds on the basis of opposition reflects a parallel in the Republic: at Republic V, 475e-476a it is asserted that, since the form of the beautiful is opposite to that of the ugly, they are two

never had difficulties to distinguish identification from attribution: the theory of participation, whatever its shortcomings, has no difficulty in accounting for false statements. Where Plato does consider the confounding of identity and attribution, it is uniformly deemed a piece of sophistry. (See, for example, Euthydemus 298c-d, Philebus 14c-d.) The issue in the Sophist is not how to discover an account for false statement, but rather what is the source that can give the sophistical challenge to the possibility of false statement a thin patina of plausibility. It is, therefore, not about grammatical weaknesses or logical stupidity, but about examining metaphysical error.

465 The "kinds" are explicitly taken as distinct individual forms, and, with the example of "difference," it will be acknowledged that a "kind" can admit of "parts," each of which is itself likewise a "kind."

466 Cornford (1935), without offering justification, asserts that the communing of bodies with generation and soul with reality posited by the friends of the forms is just verbal happenstance, rather than the same concept of one related to the communion of forms. 
and each is one. The passage also mentions "communion"; however, unlike the present discussion of rest and motion, no qualms are raised about their opposed natures preventing some kind of mutual communion: each in itself is one, but appears many through communion with actions, bodies and each other, an account also said to hold for "just and unjust, good and evil, and all the forms." Unproblematic in the Republic, the communion of kinds now in the Sophist becomes an issue, precisely because, under the Visitor's Eleatic presuppositions, no distinction is drawn between form as reality and that which participates in form as dependent entity, not fully real in the same sense as forms. ${ }^{467}$ The Republic distinction between that which is and that which is between being and not-being is, of course, one way to drawn a distinction between being and having a character.

Once in the Sophist "rest" and "motion," have been set apart, each subsequent distinction of kinds that is made will both assume and deny the distinction between being a character and having a character.

"Rest" and "Motion" distinguished

1) "Rest" and "motion" do not mix. (254d7)

If either had the other as an attribute, then it would imply that it is the other, which would be contradictory, since they are opposites. The Visitor's denial of their combination, of course, does not specify this or any other reason, but is a simple reiteration of the earlier agreement, based on the opposition of "rest" and "motion". One could certainly construe the claim that the two never combine in a way that avoids a conflation of being a character with having a character, if, that is, one were to specify the respect in which it is understood that they do not combine. But that is precisely to presuppose the absent distinction. The differentiation of the five kinds is throughout muddied by the ambiguity over just what it is that the name of any "kind" actually names: continuing the pattern of thought that produced the preceding puzzles over "being", all of the kinds now, like "being" before, are taken simultaneously as one, that is, a name for a distinct individual nature, and as many, that is, as a whole of parts or a sort of class name for every entity to which the name can be attributed.

"Rest," "Motion," and "Being" distinguished

2a) "Rest" mixes with "being", and 2b) "Motion" mixes with "being". (254d12)

Because both are, which in turn is taken to imply that each kind ("rest" and "motion") has being as an attribute, or participates or mixes with being, but is not identical to being, which would lead to contradiction. Therefore,

3) "being", "rest", and "motion" are three. (254d12)

The conclusion rests on denying the distinction in the first step and simultaneously accepting the distinction in the second. ${ }^{468}$ That is to say, the first step

\footnotetext{
467 The strikingly neutral sense with which "communing" and "blending" (summignusthai) is used here alongside terms that elsewhere in Plato indicate participation in forms (metexein, metalambanein) shows that that combination in the Sophist cannot be identical to or an extension of the relation of participation that in earlier dialogues relates particulars to forms, as Heineman (1983) 175 asserts: "Plato has simply transferred to the realm of Forms the old relation of participation which holds between individuals and Forms." If Plato does this, it is not "simply," since it would entail a reversal of the ontological understanding of forms that grounded the distinction of forms from particulars in the first place.

One might seek to rescue the argument from the inconsistent implicit assumptions as follows: The mutual exclusion of "rest" and "motion" is ambiguous, as noted above. It could be read either, as here, to assert that 1) their combination would imply their identity or 2) that combination would assign to each a property incompatible with its own nature. In other words, "motion", as a property, attributed to
} 
that separates "rest" and "motion" relies on the assumption that "motion" cannot in any way be attributed to "rest" or "rest" to "motion," because the attribution would imply identity: if the kind "motion" has "rest" as a property then it is "rest." The next step in the argument assumes, incompatibly with the first, that "being" can be attributed to both "rest" and "motion" without that attribution implying identity. Consequently, 1) the three kinds are distinguished as three on the grounds that they do not overlap in their patterns of combination - "rest" combines with "being" but not with "motion," "motion" with "being" but not "rest," and "being" with both "motion" and "rest"; but 2) the resulting pattern of combinations is obtained by first implicitly denying then implicitly assuming the distinction.

The opposition of rest to motion will serve as a premise in each step of the argument distinguishing the several kinds, along with the implication that this entails the impossibility of any mixture of rest and motion, an implication that the argument, by the conclusion, will revoke.

The separation of "rest", "motion", and "being" permits the introduction of sameness and difference by identifying a distinct plurality: each of the three (as one among many) is other than the others and the same as itself. (254d14)

\section{"Same" and "other" distinguished from "rest" and "motion"}

4) Neither "motion" nor "rest" can be "same" or "other", (255a4-5) since whatever is attributed to "motion" and "rest" in common cannot be either. (255a7-8). Thus, the same argument that distinguishes "being" from "motion" and "rest" also distinguishes "same" and "other" from "motion" and "rest."

Evidently sameness and difference, in terms of the sheer extent of their mixing, are, like being, in effect, transcendentals; they are of unlimited extent. Should the pattern of combinations alone mark distinct names as naming distinct entities, then "being", "same" and "other" cannot be separated. To the extent that the pattern of possibilities for combination has been used to separate, first "rest" and "motion", then subsequently, "rest", "motion" and "being", it would follow that "being", "same", and "other" would be rendered indistinguishable, which in turn would lead to a version of the same dilemma that grounded the initial separation of "rest" and "motion": namely, "same" and "other", as opposites, should not admit of combination. Of course, from the universality of sameness and difference, it follows that they must combine. "Same" and "other" are jointly distinguished here from "motion" and "rest", and in the final two steps of the passage will individually be distinguished from "being", but the Visitor never cleanly separates sameness from difference. ${ }^{469}$

\footnotetext{
"rest", as a subject (and vice versa) would be to attribute a property that is incompatible with the essential nature of the subject; then, the attribution of "being", should it be identical to "motion", would likewise assert an essential incompatibility. Just as, to adapt an example from the Phaedo, the number 4 is neither oddness nor evenness, but has only "even" as a property and never "odd." The ambiguities attending Plato's formulation of the kinds, each of which is treated at times as a singular entity, and at times as the name for a class of individuals with a common property, evades such specificity, and so to supply it presupposes the distinction that the ambiguity is designed to disguise. But beyond this, other considerations count against such an attempt to refashion the Visitor's argument into consistency: the rejection of any combination whatever of "rest" and "motion" is grounded exclusively on their opposition, and as indicated in the Republic V 475e - 476a, and also later concluded here, opposition alone does not provide sufficient ground to prelude the possibility of combination.

The lack of a sharp division between "same" and "other" when the Visitor is so meticulous about separating the other kinds is significant-ultimately there will be no basis to distinguish them and, following the logic of the divisions, the nature of a kind, that is, what it is to be something, will be determined by difference alone.
} 
These troublesome consequences could be avoided by the distinction that the Visitor will introduce later to separate "other" from "being", the distinction between pros alla and kath' hauto. Something can "be" something in some respect. It is a distinction that implicitly invokes the lost distinction between being a character and having a character. A thing cannot be (identical to) a character partially, in some particular respect, but very well can possess character in some respect.

The distinction only comes later, but the necessity of a means to draw the distinction is foreseen already at 255a7: whatever we attribute (proseipomen) to rest and motion in common (koineii) can be neither (oudeteron autoin hoion te einai). It is a more explicit formulation of the reason that was used to distinguish being from them.

While this claim distinguishing sameness and difference from "motion" and "rest", on the surface, is a more direct invocation of the distinction that has been obscured, it is also, in is entirety, a more explicit repetition of the pattern of reasoning that justified the initial distinction of the first three kinds. And so, in the same way as previously, it simultaneously 1) implies a distinction between having a form and being a form-"same" and "other" must mix with both "rest" and "motion" without therefore being either "rest" or "motion"—and also 2) implies the denial of the distinction - the conclusion that the identity of a character that is attributed to both "rest" and "motion" with either would entail the identity of "rest" and "motion". Curiously, then, the reason supplied for the distinction rests on the assumption that the distinction does not obtain.

"Being" distinguished from "same"

5) The same pattern of reasoning, simultaneously assuming and denying a difference between having and being a form, justifies the distinction of "same" from "being". It again exploits the prior assumptions about the opposition of "rest" and "motion", with the kind "being" providing a connecting bridge to the pair.

5a) "Same" cannot designate the same kind as the word "being" does. Since it has already been asserted that sameness mixes universally, and that, like other kinds, "being" is the same as itself, this assumes that for "being" to have the character of sameness can be distinguished from the assertion that it $i s$, that is, it is distinguishable from its being identical to the character of sameness.

5b) Otherwise, if "being" and "same" did mean the same thing, a contradiction would follow. (255b11-c1) Assume that "being" and "same" mean the same. ${ }^{470}$ Then "being" would both have sameness as a characterizing form ("being" is the same as itself, just as the kind "same" is the same as itself, and so on); also, it would be the same kind as sameness, and to state that something is would be equivalent to stating that something is the same.

Just how to construe the sense of an equivalence (that is, the equivalence between "being" and "same" that is rejected here) is left vague. There is an evident sense to statements such as "Socrates is" or "Unicorns are" that does not extend to some attempted statement such as "Socrates is the same," which calls for completion by specifying the respect in which sameness is said of Socrates. ${ }^{471}$ As we have seen, however, the line of argument, a crafted study in ambiguity, is mute on suchlike, and will make argumentative use of its silence. That sameness and difference are correlates has already been implied in the assertions that every distinct individual is the same as itself and different from other distinct individuals. The explicit distinction between that

\footnotetext{
$470 \quad$ Here the word semainein is used. There is no indication that would justify imputing some demarcation of meaning from reference: semainein, to designate, is to designate some thing.

$471 \quad$ As noted by others, e.g., Bostock (1984) 91.
} 
which is in itself and that which is with respect to another awaits the distinction of the final kind.

5c) Since, then, both "rest" and "motion" are (from the initial assumption), it follows that the identity of "being" with "same" would imply that "rest" and "motion" are the same, and consequently, if the ambiguities are left unresolved, the contradiction would follow that "rest" moves and "motion" rests. That would violate the assumption that, as opposites, "rest" and "motion" do not mix in any way. It therefore assumes that no distinction between having and being a form obtains. It is the conclusion opposite that reached by a parallel line of reasoning when it was agreed that both "motion" and "rest" do combine with "being." The imputation that things stand otherwise when it is now a question of combination with "same" is reinforced by the play upon the ambiguity in the meaning of "same," namely, that when we consider the assertion "Rest and motion are both (the) same," we might just assume the unwarranted completion: "as each other" rather than "as themselves."

Alternatively to reading this step in the argument as a renewed conflation of having a character with being a character, one could read this fourth step globally as a reductio starting from the assumption that the distinction does not obtain and arguing to a contradiction, implying that the distinction must be made. In that case, the argument leads up to the pros alla - kath' hauto distinction, which will be made next. However, the concluding step in distinguishing "being" from "same" works only on the assumption that the distinction between being and having a character must be made and denied simultaneously. If that is, we remedy the ambiguity about the meaning of "same" (which the text does not do at this point), then we would need other grounds and a different argument to separate "being" from "same." Moreover, as will be seen, the pros alla - kath' hauto distinction will not be immune to the Eleatic difficulties that have accompanied the reasoning thus far.

Before proceeding to the separation of "being" from difference, one further note of elaboration on the preceding observations is in order. In light of the play about the ambiguities of "same," there are two possible salient readings of the conclusion that separates "same" from "being."

On the first reading, the concluding step allows that "motion" and "rest" both are, that is, both mix with the kind "being," thus assuming the distinction, while asserting that the identification of "being" with sameness would render the opposites "rest" and "motion" identical, thus denying the distinction.

Alternatively, one could read the concluding step not as a logical inference that is based on the conflation of a distinction, but as a verbal one that exploits an ambiguity in the word "same." If "being" is the same as "same," then the statement that "'rest' and 'motion' are" is equivalent to the statement that "'rest' and 'motion' are the same." It is a reading more evocative of outright sophistry than failed logic, and yet it represents a sort of verbal equivalent of the simultaneous affirmation and denial of our distinction. "Same," unlike the previous kinds, is a relative term: whatever is same is the same as something or same in some respect, and the possibility of relations requires the possibility of having a form without being that form. At the same time, the omission of any specification of respect in the implication that "'rest' and 'motion' are the same," obscures the same distinction, giving it the appearance of an identity statement.

"Other" distinguished from "being" 
6) Both "same" and "other" were separated from "motion" and "rest" with one same argument. An extension of that same argument served to distinguish "same" from "being". ${ }^{472}$

Nothing would prevent a further application of the argument to "other" if we follow the first reading: if "rest" and "motion" are both "other" (i.e., identical to the kind "other"), then they are both the same (i.e., identical to each other) which contradicts the initial premise that, as opposites, they absolutely cannot mix. ${ }^{473}$

Instead, however, the distinction of "other" from "being" is drawn in another way, explicitly designating the distinction that has been employed and denied at each step thus far: among the things that are (tōn ontōn) some are always said (aei legesthai) in themselves (auta kath' hauta), and others with respect to others (pros alla). This is the distinction of what something is as such, in virtue of itself, as opposed to what a thing might be said to be, not in and of itself, but with respect to something else that is not identical to it. In other words, the distinction outlines the separation between what it is to be a form and what it is to have a form, between character and characterized.

One might be inclined to render kath' hauto and pros alla as "absolute" and "relative." ${ }^{474}$ Elsewhere in Plato, say, for example, Republic V, the distinction captures the ontological opposition of being and becoming, that is, the reality of forms as compared to the nature of the existence of particulars that participate in forms, and so, as participants, are what they are not in themselves but with respect to other things. ${ }^{475}$ And so, if the distinction is to hold any ontological import, and is not simply a grammatical distinction, then "absolute" and "relative" (or other terminological variants, such as "complete" and "incomplete") are inadequate, for too narrow. It indicates something broader, such as the Platonic distinction between what it is to be a form from what it is to participate in form or the Aristotelian distinction of essential from nonessential predication. For example, a statement such as "Socrates is small" must be understood as indicating "small" relative to someone larger, or to an average height. However, statements such as "Socrates is ugly" or "Socrates is barefoot" are not relative, but also not equivalent to, say, "Socrates is this individual human." Thus, in "Socrates is ugly," "ugly" is not said kath' hauto. Socrates is not ugly in virtue of being Socrates; after all, with a little botox and plastic surgery, he just might be made both Socrates and beautiful. It is a relative attribution, not like "large" but as the relation of particular to universal that is not that particular. It is not said as such, but rather in some respect. Socrates is ugly, not as ugliness is ugly, but with respect to the standards of

472

It would not function for "other", insofar as the previous argument relied on the confusion lurking in the ambiguous statement that "'rest' and 'motion' are the same." This is noted by Malcolm (2006) 276.

And so, it is not strictly speaking the case that, as Malcolm (2006) 276, states, the prior argument cannot be extended to the distinction of otherness, thus requiring the pros alla - kath' hauto distinction. Malcolm is correct insofar as the on the surface the seeming discrepancy between the two equally ambiguous statements "'motion' and 'rest' are the same" and "'motion' and 'rest' are different" provide a device for introducing the pros alla - kath' hauto distinction, yet the distinction was implicit before, even if it is only made explicit now.

474 Perhaps the most widely defended view of the pros alla - kath' hauto distinction, advocated in modern times by Campbell (1867), Cornford (1935) and many since. Frede (1967) gives a survey. The interpretation defended here, though avoiding as potentially misleading the terms "absolute" and "relative," might also be assigned to this group, provided we do not lose the ontological dimension to the distinction and equate it to a distinction between complete and incomplete uses of "is."

475 The interpreter who would follow the tradition of a grammatical or logical reading of the passage will want to deny any such connection of the pros alla - kath hauto distinction to a pros $t i-k a t h^{\prime}$ hauto distinction, despite the fact that pros alla and pros ti are often equivalent. (Cf. Philebus 51c) See Malcolm (2006) 283-284. 
human beauty, and so, pros alla. Furthermore, if we are to assert that a given entity is "the same as itself," then the attribute "same," grammatically a relative term, is attributed not pros alla but kath' hauto. It might be added, however, that this remark makes for a much cleaner fit to Platonic ontology than to Aristotelian, for whom there is no separation - the form itself is at some level nothing other than the immanent form. ${ }^{476}$ And yet, while the distinction evokes its ontological background, it does not, here, reclaim it: the ontological nuance of participation has been replaced with the neutrality of combination, the interval between original and image leveled out. ${ }^{477}$

If the manner of distinction that separated sameness from "being" was honed to the ambiguities that exploited the meaning of "same" (namely, the meaning of "same" as a relative in the proper sense), the current step follows suit with respect to the meaning of "difference".

The Eleatic Visitor now asserts, in words of broadest ambiguity, that "Other is always with respect to what is other" (to d' heteron aei pros heteron). (255d1)

What sense can be given to the assertion? While the kath hauto - pros alla distinction suggests a means to disambiguate what may be said of a thing in itself as contrasted with what may be said in some respect, the assertion, twice repeating heteron, is itself vague as formulated, precisely because (just as with the employment of terms designating the previous kinds) to heteron could be construed to mean 1) otherness as a kind, or 2) that which is characterized as being other, in other words, either otherness in itself, or otherness with respect to something else that may be said to have otherness as a property.

Among possible construals of this equivocation, two stand out. On the surface at least, the interlocutors are investigating "the other" as a kind, an individual entity. In that case, to heteron pros heteron would mean something like: otherness is what it is with respect to otherness. That is, the statement might be taken as an expression, applied to "other", of the general claim that every kind is the same as itself; the assertion that otherness is what it is to be other. It would then be an assertion of the "nature," the physis of otherness. The notion of the nature proper to a kind, implicit in the initial opposition of rest and motion, will be invoked repeatedly in the subsequent exchanges summarizing the separation of kinds. Moreover, if to heteron is construed here as a kind, as a form or entity of sorts, then, unless the assertion that "other is always with respect to other" contradicts the claim, both made earlier and repeated later, of the universality of sameness, then this expression of the nature of otherness has the paradoxical implication that "other" in itself is difference with respect to others: the kath' hauto is the pros alla, in a quasi denial of the distinction just introduced to illustrate the so-called nature of otherness.

If instead we take the statement as an assertion, not about otherness as a kind, but about the class of things that are other, that is, about other as a character that things (including perhaps but not limited to otherness itself) have, then we obtain a different reading of the statement, but again one that echoes through the subsequent summary. Then, to heteron pros heteron means: whatever is other, that is, whatever has the property of being other than something else, has that property with respect to otherness

476 It might be noted in passing that the expressions kath' hauto and pros alla are referred to as forms (eidoin), 255d4, that can be participated in, mimicking one of the terms used to designate the kinds, but are not in turn distinguished as an additional two kinds.

477 In this regard, see Malcolm (2006) 279-280 for a clear criticism of Frede's attempt to restrict kath hauto to statements where a form is the subject. While the inclination to do so would make sense in the context of an exposition of the theory of forms and relation of forms to particulars, it does not fit the Sophist passage. 
as a kind. This construal is mirrored in the conclusion at 255e that the "other" mixes with every kind, and that each of them differs from all others, "not by its own nature" (ou dia tēn hautou physin), but by participation in the "other".

Where the first rendering posits a so-called "nature" of difference that undoes the difference between what a thing is in itself and what it is with respect to others, since the "other", by its own nature, is always pros alla, the second rendering effaces altogether the idea of a positive and distinct nature: each and every thing is just what it is by its difference from what it is not. The differentiation of the megista gene has presented an abstract logic underpinning the divisions, where definition is exclusively negative. ${ }^{478}$

In doing that, the examination of the megista gene also provides a dialectical bridge to the resolution, such as it is, of the dialogue. The identification of "other" with "not-being" ought, one should think, to imply the identification of being" with "same". But that may seem problematic, given the previous distinction of "being" from "same" and now the assertion that "not-being" is not the opposite of "being". In that case, the identification of "other" with "not-being" ought instead to imply the identification of "being" with the "not-other". Either to accept or to reject the implication appears problematic. Not to draw the inference would entail the unacceptable result that the uses of the term "being" in the affirmative kind "being" and the negative "not-being" are utterly equivocal. If that consequence is not contradictory, it is certainly incoherent; it would mean, for example, that the "is" in "Theaetetus is flying" and the "is" in "Theaetetus is not flying" have an entirely different sense. Moreover, insofar as all types of "not-being" are accorded a spot among the things that are, such equivocation between "being" and "not-being" is surely precluded. On the other hand, if "being" is the "not-other", then "being" is both "other" and "not-other" in the same sense, namely, as not the "other", which is to say, different from the kind "other".

Even if we should find a way to finesse these troublesome implications about this possible identity of two nominally distinct kinds, the dialogue's further explication of the kind "other" leads directly to analogous implications that hold globally for all kinds in general, not only the contrast of "being" and "not-being." At 256c, an inference is drawn: "according to the present argument motion is in a way not other and in a way." The Visitor leaves it to us to spell out the respect in which it is not and is: namely, motion (and, indeed, every kind) is other, since it is one entity in itself distinct from, or other than, every other kind; it is also not other, because motion (and every other kind, apart from "other" itself) is a kind in itself that is distinct from the "other," which is also a kind in itself. The "discovery" of the "other" as a kind holds consequences for the understanding of "being," that is, for what it means for any part of being to be an entity in itself. Just how insidious these consequences are and their full implications for the assertion that the argument shows "motion" to be "in a way other and in a way not other" only become evident when we take into consideration how otherness is analyzed and how it stands with respect to other kinds.

The "other" (thateron) is designated as a kind, an eidos or a genos at $255 \mathrm{~d}-\mathrm{e}$ : "the nature of the other must be counted among the forms that are" (tèn thaterou phusin lekteon en tois eidesin ousan). Placing it explicitly among things that are foreshadows the assertion at $257 \mathrm{~b}$ that "not-being" (to $m \bar{e}$ on) does not designate an opposite

478 The divisions of the Sophist, in contrast to the instructions for proper division in the Politicus, proceed by blunt dichotomy, not dividing "at the natural joints," (Politicus 287c, cf. Phaedrus 265e) each step separating the object of definition from what it is not. Division in the Sophist is definition by negation, the only type of determination of "nature" that the analysis of combinations ultimately will allow. See Ambuel (2007); cf. Dorter (1994). 
(enantion). The acknowledgement that the "other" has a nature in itself as a distinct entity is followed immediately by the assertion, both most curious and most significant, that every distinct entity differs from every other entity "not by its own nature, but by participation in the idea of the other" (ou dia tèn autou phusin, alla dia to metechein tès ideas tês thaterou). Consequently although an unspecified "nature" is imputed to every kind, no kind differs from its opposite or from any other kind by its own nature; rather, in all instances of otherness the difference is by the nature of the "other,"

It follows that this applies to the distinction between "motion" (or any kind except "other" itself) and otherness as well. Therefore, when we spell out in greater detail the relevant senses in which motion is "other in a way and not other in a way," we obtain:

1) "Motion" (or any genos except "other") is other by participation in otherness with respect to the other; and

2) "Motion" (or any genos except "other") is not other by participation in otherness with respect to the other.

"Motion" or whatever you will is, therefore, both other and not other in the same manner and in the same respect.

One could respond that the two statements do not, in fact, express otherness in the same respect. In the positive formulation, "motion" is said to be other than otherness, and that is a predicative statement, attributing the property "other" to the kind "motion." On the other hand, in the negative formulation, "motion" is said not to be the "other," and that means that "motion" and "other" are not identical. So the first statement is an attribution, the second an identity statement; or, perhaps, the first is about having a property, the second about being a property.

But this attempt to rescue consistency by resorting to a version of the distinction that has been simultaneously drawn and denied with artful ambiguity throughout the passage will not stand up to inspection. Consider an alternate example: "Red is not green." Abiding by the stipulations about the nature of otherness, this difference is explained not by the nature of red and of green, but by the participation of red in the "other" with respect to green. Therefore, "Red is not green" is equivalent to "Red is other by participation in otherness with respect to green." To make the quandary clear, if we now substitute the kind "other" for the kind "green," we obtain the equivalence of statements of forms 1) and 2) above namely: "Red is not other" is equivalent to "Red is other by participation in otherness with respect otherness."

Although an unspecified "nature" is imputed to every kind, no kind differs from its opposite or from any other kind by its own nature; rather all instances of otherness are by the nature of the "other". This is joined to the further assertion that the complement of any kind is to be counted as a being, an entity among the things that are as real, as much "one" and as much entity with its own nature in itself as every other kind. Thus, if, say, "the beautiful" is a kind and is one, so too is "the not-beautiful," which must include, not only "the ugly," but also, "the round," "the green," "the barefoot," "the attractive," and so forth. The distinction of kinds loses all definition: a thing is what it is not, and, after the failure to clarify "not-being" or "being", the Eleatic Visitor has indeed, as indicated, taken both together. The Sophist concludes, not with a portrayal of philosophical dialectic, but of an Eleatic logic that abstractly illustrates the logic of the initial divisions, which proceed entirely by negative definition: a thing is what it is not.

The analysis of the "other" as a form that can lead to an answer in the hunt for "not-being" is embroiled in contradiction. Beyond this, however, its physis, the nature of the "other" as the Visitor sketches it, has consequences that are not confined to the 
interpretation of the genos "other" alone; rather, the subsequent passages show that the "nature" of "other" determines the "nature" of all kinds.

Once having established that "motion" is in a sense other and in a sense not other, the Visitor offers the cryptic assertion that, with respect to each of the forms, "being" is many, "not-being" unlimited in number. (256e: peri hekaston ara tōn eidōn polu men esti to on, apeiron de plethei to me on.) The sense of this remark can be tied to the Visitor's next step, which is intended to illustrate how "not-being" construed as "other than being" need not be opposed to "being," but in fact can be understood as one part of being. To designate something "not-great" (to mé mega) does not mark it as small, rather than equal. Consequently, the "not-great" is not the opposite (enantion) of the "great." Furthermore, there is nothing in the text to confine the term to me mega to some determinate wider genus, such as "size." The Visitor asserts that "not" (to me kai to ou) indicates any of the things that are other than that which is designated by the expression without negation. (257c) It follows that the "not-great" (and analogously for the "not-small," "not-being," etc.) refers to the logical complement of the "great," which includes, therefore, both the "small" and the "equal," but also "rest," "motion," "being," "beautiful," and so forth. The Visitor adds (257c) that every instance of otherness - the "not-great," or the "not-beautiful," etc.-is a part of the form "other," each part of which possesses a distinct nature with its own unity. The Visitor makes this inference explicitly with the example of the "beautiful" and the "not-beautiful." (257d-258a) Since the nature of the "other" (he thaterou physis) really has being no less than any other kind, each of its parts must really be, no less than any other kind. (258a) Since, then, the complement of any form (for example, the "not-great," which includes the "small," the "equal," the "beautiful," and so on) is likewise a form and just as much as any other form a being in itself with unity and a distinct nature, it follows that any collection of parts whatsoever is also a form.

This results holds unmistakeable implications for what it means to be a part of "being" and to have a "nature." It leads directly to the already asserted unlimited multiplicity of "not-being," (256e) and that in the following way. First note that all entities that are kinds or forms in themselves are also parts of multiple forms, each of which is itself one in and of itself. For example, the "small" and the "beautiful" are both parts of the "not-great," but also both are parts of "not-being" and "not-rest," and so forth. Since, then, there is a form "not-great" that is not the opposite of the form "great," but is a part of the form "other," there must also be a form that is the "not-notgreat." The "not-not-great" cannot, of course, be identical to the "great," because "great" and "not-great" are not opposites. This becomes clearer still if we consider: the "small," which most certainly is not a part of and is other than the "great," is consequently a part of the "not-great," but the "small" must also be a part of the "notnot-great" since it is itself a distinct form that is other than the form of the "not-great." Therefore, the must also be a form of the "not-not-not great." and so on, ad infinitum.

To return, finally, to "being," "not-being," and "other": what, then, constitutes the unity that is the nature of any reality, of any part of being, each of which is one in and of itself? It follows from the determination of the nature of "other" that, while "notbeing" is not the opposite of "being," the "other" and its parts all include opposed natures within their nominally unitary natures. "Motion" and "rest," or the "beautiful" and the "ugly," are all together parts of the single nature that is the "not-great," as well as of innumerable other distinct forms.

What ultimately does it mean then to "be" a distinct form? It follows that "nature" is undeterminable as any sort of essence; rather, the nature of anything that is, is determined exclusively by what it is not. This will provide, not an account of the 
image and snare for the sophist, but an image of the image, providing an awkward means to distinguish the truth of "Theaetetus sits" from the falsity of "Theaetetus flies," but no means to explain the truth or falsity of statements such as "Theaetetus is" or "Unicorns are not," or "Images are real but not really real."

In short, the nominalism of an Eleatic metaphysics (or of a Heraclitean metaphysics, as they are interpreted in the Sophist and the Theaetetus) cannot state what anything "is", which would require the means to conceive of a character that is universal, distinguishable from things that are characterized by it, and attributable in the same or in related senses to a plurality. Consequently, what a thing "is" becomes what it is not. The analysis of combinations furnishes the abstract, if contradictory, logic underpinning the method of division used to pursue the sophist. The irony is that, by setting aside the ontological inquiry into the opposite of "being" and identifying "notbeing" (in one sense) with "other," as a result the being and nature of anything is constituted entirely by its difference from what it is not. Being, in effect, is nothing other than not-being. 